an explicit, overarching goal. The challenge of genderfair education is not simply to provide women students with the best education possible but to create an enabling environment in society.

Some major instruments of gender-fair education are affirmative action and quota systems, aggressive recruitment of female faculty and administrators, reform programs to remove bias from curricula and teaching materials, gender-sensitivity training for teachers and counselors, a review of policies and procedures for possible gender bias, and active recruitment of women into nontraditional fields of study. Also important are the identification and projection of role models among faculty, administrators, and alumnae; systematic inclusion of women among speakers and resource persons for campus events such as graduation; setting up of policies and mechanisms to handle sexual harassment cases; support services to alleviate the double burden of women on campus and to make campuses more family-friendly workplaces.

Women and gender studies programs and centers are important institutional mechanisms for gender-fair education. In addition to offering courses, these programs and centers do research, design and conduct training programs, and publish books and monographs. There should be efforts to link up with women's nongovernmental organizations and activists for women's empowerment. These partnerships are not only valuable models of cooperation and synergy but they also lead to high impact advocacy and action aimed at the larger sociocultural and political environment.

The challenge of gender-fair women's higher education should be the transformation of women's lives as well as the transformation of society itself.

\section{Women's Colleges and Universities in International Perspective}

\section{Francesca Purcell and Robin Matross Helms}

Francesca Purcell is a policy analyst at the Massachusetts Board of Higher Education. E-mail: fpurcell@bhe.mass.edu. Robin Matross Helms is a doctoral candidate in higher education administration at Boston College and is on the staff of the Institute for International Education.E-mail: matrosro@bc.edu.

$\mathrm{W}$ omen's colleges and universities play an important role in the higher education of women in many countries worldwide. Approximately 1,200 of these institutions can at present be found in Asian countries (e.g., Korea, the Philippines, Bangladesh, Pakistan, and India); in Middle Eastern countries (e.g., the United Arab Emirates and Iran); in Western countries (e.g., the United States, Canada, and England); and in the African country of Sudan. In each of these countries, the history and purposes of women's colleges are broad and varied, dependent upon local and national contexts. This article provides a brief background of women's colleges and universities in an international perspective and highlights some of the findings from a recent research initiative on this topic undertaken at the Center for International Higher Education at Boston College.

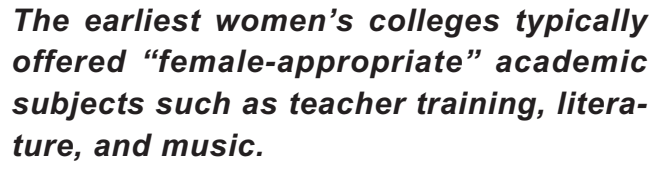

Evolution of Women's Colleges and Universities

Some of the earliest women's colleges date back to the early and mid-1800s, while the most recent ones have been founded in the past two years. Across cultures, the earliest women's colleges typically offered "female-appropriate" academic subjects such as teacher training, literature, and music. The schooling these early students received had as much to do with preparing them for their futures as wives and mothers as it did with academic development. Internationally, as more women began to work in the public sphere and take on roles outside of the home, women's colleges expanded and diversified their curricula and programs to meet these new demands. Long-established women's colleges now offer a much wider and deeper range of courses and activities than they did in the past.

The number of women's colleges and universities has declined in many Western countries (e.g., the United States, England, and Canada) over the past three decades as coeducational institutions have become the norm. Countries in Africa, Asia, and the Middle East have simultaneously been taking steps to establish women's postsecondary institutions, in response to increasing demands for women's higher education. For example, recently efforts have been made to establish new women's colleges in Afghanistan, Bangladesh, Bahrain, Kenya, and Zimbabwe. The missions of these institutions are dedicated to educating women in various fields including technology, medicine, and business, underscoring the contemporary promise of these singular institutions in the provision of tertiary education to women. 


\section{Debates over Women-only Institutions}

The legitimacy of women-only colleges remains a hotly contested topic in many countries, despite a growing body of U.S.-based empirical research literature outlining the advantages and disadvantages of women's colleges. Critics assert that women's colleges perpetuate inequalities between men and women, do not prepare women for the integrated world after college, relegate women to traditionally feminine areas of study, and are inextricably linked to the legacy of separate and inferior roles for women. Proponents contend that women's colleges provide supportive climates that prepare women more effectively for postcollege life. Women's colleges instill in women an awareness and critical understanding of women's issues, thereby enhancing women's empowerment, self-esteem, and leadership skills. In countries with restricted access for women to higher education, women's colleges open doors to women seeking higher education that would otherwise be closed.

These arguments over the pros and cons of women's colleges vary from country to country, and from region to region within countries. The debates inspired over the existence of women's colleges involve not only local economic and political circumstances but also fundamental questions of the differences between men and women, culturally and religiously appropriate gender relations, and the role of women in society.

\section{An Initial Portrait}

In order to gain a fuller understanding of the standing of women's colleges and universities across the globe, we distributed a survey to over 300 of these institutions worldwide and received completed responses from 126 of them. We asked respondents about general topics such as institutional missions, tuition costs, and types of degrees offered, as well as information on student and faculty demographics.

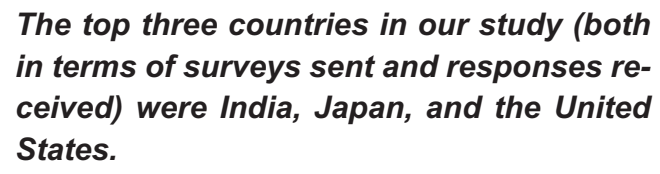

Numerically, the top three countries in our study (both in terms of surveys sent and responses received) were India, Japan, and the United States. Together, these three countries comprised 88 percent of the total number of responding institutions. Comparing and contrasting the "prototypical" institutions for each of these countries, which seem to have the highest number of women's higher education institutions in the world, provides a useful first portrait of both the similarities and regional and cultural differences of women's institutions worldwide.

In India, the prototypical institution is urban and not religiously affiliated. It relies on a combination of funding sources, including the government, the University Grants Commission, and a small amount of student tuition and fees (about $\$ 274$ per year). The enrollments are comprised of about 1,200 undergraduate students and 400 graduate students. Overall enrollments have increased in the last five years. The most popular fields of study among students are commerce, arts, science, and computer science.

\section{In India, the prototypical institution is urban and not religiously affiliated.}

In terms of faculty, India boasts the highest proportion of female full-time professors of the top three countries in our survey. The average Indian institution employs about 50 full-time professors, nearly 80 percent of whom are women, as well as 10 part-time faculty, about 50 percent of whom are women. The student/faculty ratio is $24: 1$, and just over 50 percent of upper-level managers are women.

In contrast to India, in Japan tuition is overwhelmingly the major source of funding for respondent institutions, so the prototypical Japanese women's college is funded almost entirely by student tuition, which amounts to around $\$ 8,600$ per year, plus about $\$ 5,878$ for room and board (though many students live off-campus). Colleges are typically located in an urban or suburban area, with undergraduate enrollments of around 2,111 and graduate enrollments of only 69 students. Enrollments have either remained the same or decreased in recent years, which is consistent with Japanese demographic trends. In sharp contrast to the science and business focus prevalent in India, the most popular fields of study in Japan are more traditionally "feminine": English language and literature, Japanese language and literature, education, and psychology.

In terms of faculty, the prototypical Japanese institution employs 116 faculty, 42 percent of whom are women. Part-time faculty outnumber the full-timers; there are 143 part-timers, 39 percent of whom are women. The student/faculty ratio is 18:1, and just 22 percent of upperlevel managers are women.

Like its Indian and Japanese counterparts, the prototypical American women's institution is located in or near a metropolitan area. It is almost certainly private, but it is difficult to predict whether or not it has a religious affiliation (of the schools that responded to the survey, 21 
are religious and 20 are not). As in Japan, tuition is the major source of funding, and costs students about $\$ 17,000$ per year plus an additional $\$ 7,000$ for room and board. Endowments and gifts or donations are also important sources of income for institutions.

The prototypical U.S. institution enrolls on average 1,246 undergraduates and 520 graduate students (if it offers graduate programs). Enrollments have either increased or remained the same over the last five years. Regarding academic interests, American students are a blend of their Indian and Japanese counterparts; the most popular fields of study at the prototypical U.S. institution are business, psychology, education, English, biology, and nursing.

In terms of the professoriate, the average American institution employs 92 full-time faculty, 63 percent of whom are women. In addition, it employs 76 part-timers, among whom the proportion of women is almost identical to that of the full-time faculty (65 percent). The student/faculty ratio is 11:1, and 73 percent of upper-level managers are women.

\section{Women's institutions in the three countries share a few key dimensions, but overall the differences outweigh the similarities.}

Women's institutions in the three countries share a few key dimensions, but overall the differences outweigh the similarities. In terms of commonalities, in all three countries women's institutions are mainly urban or located near metropolitan areas. Reflecting a trend in higher education worldwide, a portion of the faculty in all countries is part time. In terms of differences, the main sources of funding vary considerably, ranging, as mentioned earlier, from tuition in Japan to government funding in India. There is a wide disparity in academic focus, from business and technology in India to more traditionally "female" subjects such as education and literature in Japan. Institutional missions vary along similar lines, from "impart education in the field of applied sciences such that women develop skills which will allow them to gain employment or start their own enterprises" to "educate a woman so that she can upgrade her father's home and family and her husband's home and family." In addition, large differences were found in the percentage of managers who are women, which likely reflects cultural and historical differences among the three countries.

\section{A Call for Further Research}

The results of our study give a general picture of women's colleges and universities worldwide and provide important comparisons among countries and in- dividual institutions. However, much more research is needed, for which this study is intended to serve as a starting point. We hope that our findings will inspire other researchers to learn more about this very important segment of higher education.

Women's Colleges and Universities in International Perspective: An Overview, by Francesca B. Purcell, Robin Matross Helms, and Laura Rumbley, will be published by the Center for International Higher Education at Boston College in September 2004. To request a copy, please e-mail Laura Rumbley at rumbley@bc.edu.

\section{Private Universities in South Korea}

\section{Seung-Bo Kim and Sunwoong Kim}

Seung-Bo Kim is a doctoral student at the KDI School of Public Policy and Management. Address:207-43, Cheongnyangni 2-dong, Dondaemun-gu, Seoul 130-868, Korea.E-mail: skimbo@hanmail.net. Sunwoong Kim is professor of economics at the University of Wisconsin Milwaukee. Address: P.O. Box 413, Milwaukee, WI 53201, USA. E-mail:kim@uwm.edu.

South Korea (Korea hereafter) has experienced a spectacular expansion of higher education during the last five decades. In 1950, the number of students enrolled in higher education institutions amounted to just 11,358. In 2002, 52 years later, enrollments had increased to more than 3.5 million, and more than 40 percent of the age cohort is enrolled at four-year higher education institutions. Even in a period of global massification of higher education, the Korean experience is particularly spectacular.

Throughout this rapid expansion, the private sector has played a vital role in the supply of higher education, as the government has concentrated its scarce resources into the speedy implementation of universal primary and secondary education. As of April 2002, there were 159 two-year junior colleges and technical colleges in Korea. Out of these 159, 143 were private institutions, accommodating more than 95 percent of students. At the same time, there were 163 four-year colleges and universities, 137 of them private. Out of about 2 million students enrolled at four-year universities, three-quarters of them were in private institutions.

\section{Reliance on Tuition}

The rapid expansion of higher education by utilizing the private sector comes with substantial structural problems. First, the overall quality of education is considered to be low, while the prices paid by students are 